\title{
Introducing the Penn State World Campus through Certificate Programs in Turfgrass Management and Geographic Information Systems
}

\author{
Alfred Turgeon, David Di Biase, Gary Miller \\ The Pennsylvania State University
}

\begin{abstract}
This paper describes two of the distance educational programs-Turfgrass Management and Geographic Information Systems-offered through the Penn State World Campus during its first year of operation in 1998. Detailed information is provided on how these programs were selected and supported, the nature of the students who enrolled and the faculty who developed and taught the courses, and the technology and infrastructure employed for delivering content and engaging students in collaborative learning. The organization of the World Campus, the evolution of these programs, and the results obtained from them during the first 18 months of operation are presented. Several contemporary issues are addressed from a faculty perspective, including: teaching effectiveness, relationship with students, satisfaction with product, compatibility with other responsibilities, ethical concerns, incentives and rewards, team efforts, support services, perceptions by colleagues, scholarly value, opportunity cost for faculty, intellectual property concerns, and compensation.
\end{abstract}

\section{INTRODUCTION}

The Pennsylvania State University has been a pioneer in distance education. For more than a century it has offered distance education courses using a variety of synchronous and asynchronous technologies, from correspondence study to cable television to satellite and interactive video. In 1992, a University-wide task force recommended that distance education be repositioned within the mainstream of the University's academic life. In 1996, President Graham Spanier appointed a study team to evaluate the feasibility of creating a new on-line campus of the University - the World Campus - that would use the Internet and other technologies to establish ALN-based learning communities around signature Penn State programs - programs for which Penn State has an acknowledged academic reputation.

All World Campus programs reside in the Colleges of the University. All academic Colleges were asked to identify programs that had potential for World Campus delivery. These were then evaluated on the following criteria:

- Academic reputation

- Readiness of the academic unit to develop the program

- Appropriateness for technology-based delivery

- Existence of an identifiable market sufficient to generate self-supporting income

- Scalability over time

Among the first two programs selected for development were an undergraduate Certificate Program in Turfgrass Management (TM) and a noncredit Certificate Program in Geographic Information Systems (GIS). 
The series of turfgrass courses comprising the TM Certificate Program are the same as those offered in the resident Turfgrass Science major within the College of Agricultural Sciences; they include: Turfgrass Pesticides (TURF 230), The Turfgrasses (TURF 235), Turfgrass Pest Management (TURF 236), Weed Control in Turf and Ornamentals (TURF 238), Turfgrass Edaphology (TURF 334), Turfgrass Cultural Systems (TURF 337), and Case Studies in Turfgrass Management (TURF 436). The first course, offered in January 1998, was TURF 235. This was followed by TURF 230 and TURF 334 in September 1998, and TURF 436 in January 1999. The remaining courses are currently under development and are expected to be available during the 1999-2000 academic year. With the exception of TURF 230 (a one-credit, continuous enrollment course), all are three-credit, cohort-based courses. Students enrolled in this program can accumulate transferable credits, continuing education units (CEUs) with 4.5 units equaling these credits toward certification by the Golf Course Superintendents Association of America, and a certificate upon satisfactory completion of at least 15 credits of coursework. The intended audience for this program is anyone interested in pursuing a career in the turfgrass industry; students have included golf course superintendents and crewmembers, landscape maintenance personnel, and undergraduate students at other academic institutions.

A second signature program selected by the study team was Geographic Information Systems (GIS) in the College of Earth and Mineral Sciences. GIS are based on specialized software tools that integrate database management, mapping, and spatial analysis capabilities. Skillful and knowledgeable GIS practitioners are valuable to businesses and government agencies that need to know where customers and resources are located, how products and services can be delivered most efficiently, and where new facilities ought to be built. The Certificate Program currently consists of four courses: The Nature of Geographic Information (GEOG 5121), Elements of GIS I: Database Creation and Management (GEOG 5122), Elements of GIS II: Data Analysis and Display (GEOG 5123), and GIS in Practice: Environmental Applications (GEOG 5124). Although comparable resident courses already existed, differences in clientele, format, and scheduling prompted the creation of new courses for delivery via the World Campus. The GIS Program launched in January 1999 with a cohort of 52 students. Each course lasts ten weeks, followed by a three-week break. Courses have been designed to entail four to eight hours of student effort each week. Students earn four CEUs per course. They can complete the sequence of four courses and earn a certificate of achievement in one year. New cohorts begin in January, April, July, and October. The intended audience includes professionals employed by local, regional, state, and federal government agencies, environmental consultancies, utilities, and others whose work involves analysis of geographic data, but who lack formal education in geography or geographic information technologies.

Courses are offered on a specific schedule, but students have great flexibility about when they choose to participate. Both the TM and GIS programs involve cohort-based, asynchronous learning networks with flexibility built into course schedules.

\section{RATIONALE}

The goal of the World Campus is to become fully institutionalized within Penn State. This cannot happen unless teaching in the World Campus is both professionally rewarding and personally satisfying. Penn State's Faculty Senate has established guidelines that ensure that World Campus and other outreach teaching is considered part of the teaching portfolio in promotion and tenure processes. The objective of building World Campus into the regular teaching load of faculty is also designed to make World Campus participation part of a faculty member's normal professional experience. At the same time, the University is committed to integrating World Campus teaching into the rest of the University's academic program. It is intended that faculty will develop and teach ALN courses for both World Campus and campus-based students in a seamless educational environment. To this end, the President has earmarked \$1 million over the next four years to support development of courses that meet both World Campus and residential campus needs.

The World Campus is part of a broader change in the use of technology in the Penn State learning environment. This raises questions about how faculty who become involved in technology-based learning environments should be supported and rewarded. Several University-wide studies are now underway, including one by an Intellectual 
Property Task Force that is examining the entire range of issues related to copyright and patents in light of the new technologies, and another by a committee that is proposing guidelines for intercampus use of on-line courses.

For faculty within the College of Agricultural Sciences, the principal motivating factors for creating the TM Certificate program were: to explore the potential for Web-based instruction for resident and distance students, to extend the reach of turfgrass educational activities to students throughout the world, and to respond to the opportunities presented by the inauguration of the Penn State World Campus. With respect to the Agricultural Sciences faculty generally, the goal was to entice faculty members to participate through the creation of effective courseware models and a support system to assist them with courseware development. For the TM Certificate Program faculty specifically, the goal was to create a comprehensive program of courses involving six faculty members and through which students could become qualified in turfgrass science and management. All faculty recruitment activities were directed at members currently within the institution. Some participated enthusiastically because they could see that it would enhance the Turfgrass Program's international reputation and provide salary supplementation or additional financial support for their academic activities. Others were either reluctant to take on new responsibilities, or felt that the benefits were not sufficient to warrant the expenditure of the required time and energy.

With respect to the GIS Certificate Program, mainstream tenured and tenure-track faculty members who specialize in GIS declined to participate because they perceived the personal and professional incentives to be inadequate. The program went forward after the Geography Department's head determined that nontenure-track faculty members were available who were willing and able to develop and deliver a high-quality program. A noncredit certificate program was proposed because department faculty members who were concerned about competition with the resident program were unlikely to approve a degree program. Geography faculty, like many other nonparticipating faculty members around campus, remain skeptical about the motives and quality of World Campus programs. Developing broad understanding of the ALN environment and how best to integrate it into the academic community is an ongoing concern.

\section{BACKGROUND}

\section{A. Institution}

As noted earlier, academic readiness was one of the key criteria for the selection of the first few programs to be developed for the World Campus. TM and GIS were uniquely positioned because participating faculty were early innovators in the use of technology.

The initiation of the TM Certificate Program in 1997 was preceded two years earlier by efforts to create Web-based learning resources to support resident instruction in turfgrass management. At that time there were very few courses employing Web-based technology at Penn State; of those that did, few contained learning resources that students could access independently. Also, as the first generation of Web editors were not as capable as those available today, innovative uses of HTML coding were often required to create instructional modules and other learning resources. Initial efforts were directed at making decision cases used in the TURF 436 course available on the Web for the 1996 spring semester. The course was offered to Penn State resident students and a group of distance students from Rutgers who were included in discussion classes via interactive television. In September 1996 the College of Agricultural Sciences provided annual funding of $\$ 75,000$ to support a new Educational Technologies Program under Dr. A. J. Turgeon's direction. In this program, a large inventory of turfgrass instructional courseware was produced and assistance in courseware development was offered to faculty from other programs and units within the College. In the fall semester of 1997 the introductory turfgrass course (TURF 235) was offered by Dr. Turgeon to student volunteers at the University Park and Berks campuses as an entirely Web-based course. Based on the results of this experience, adjustments were made in the organization of materials as well as in the sequence and frequency of activities the students were asked to perform. Thus, when the World Campus TM Certificate Program was initiated, the learning resources to support the capstone (TURF 436) and introductory (TURF 235) courses had already been developed and field-tested. 
The Certificate Program in GIS was a natural extension of existing activities in computer-mediated instruction within the Geography Department. The Department's Deasy Laboratory has played a leading role in multimedia software development for geographic education since it helped to create a series of animated historical map essays for the 1993 edition of the New Grolier Multimedia Encyclopedia. Since then it has published numerous CD-ROM titles and Web resources that foster student-centered learning. In 1997 Lab Director David Di Biase developed a Web-based general education course called "Mapping Our Changing World" for traditional resident instruction. Most Geography faculty members now use some Web-based course materials, though none were intended for use in asynchronous learning networks.

\section{B. Faculty}

Dr. Turgeon, Professor of Turfgrass Management, Department of Agronomy, is Senior Faculty Coordinator of the TM Certificate Program. He is also author and instructor of the program's introductory (TURF 235) and capstone (TURF 436) courses. He has 31 years of experience teaching turfgrass science and management, and has received several teaching and service awards. Dr. T. L. Watschke, Professor of Turfgrass Science, Department of Agronomy, has 29 years of teaching experience and is also the recipient of several teaching and service awards. He is responsible for TURF 230 and is currently developing TURF 337 and co-developing TURF 238 with Dr. Larry Kuhns, Professor of Horticulture, Department of Horticulture, who has 23 years teaching experience. Andy McNitt, Instructor in Turfgrass Science, Department of Agronomy, is responsible for TURF 334; he has 14 years of teaching experience. Dr. Paul Heller, Professor of Turfgrass Entomology, Department of Entomology, has 20 years of teaching experience and shares responsibility for developing the TURF 236 course with Dr. Wakar Uddin, Assistant Professor of Turfgrass Pathology, Department of Plant Pathology, who has three years of teaching experience.

David Di Biase, Senior Lecturer in Geography, is Faculty Coordinator of the GIS Certificate Program. He is also author and instructor of the Program's introductory course. He has 10 years of experience teaching cartography and geographic information science, and has received national and university awards for innovation in computer-assisted geographic education. His World Campus responsibilities account for $60 \%$ of his time. Dr. Todd Bacastow, Senior Research Assistant affiliated with Penn State's Environmental Resources Research Institute and an Adjunct Assistant Professor of Geography, has had 20 years experience in mapping and geographic information systems as an officer in the U.S. Army, and eight years experience as an instructor at the U.S. Military Academy and at Penn State. His participation in the World Campus accounts for $40 \%$ of his time. Barry Evans is also a Senior Research Assistant with the Environmental Resources Research Institute who spends $25 \%$ of his time developing and teaching World Campus GIS courses. He has more than 20 years experience in GIS applications and training at Penn State and in the private sector. The program also supports two full-time faculty research assistants-David Walrath and Jason Cupp - who are responsible for developing custom GIS software applications and tutorials, and for responding to students' software-specific inquiries. A Deasy Lab staff member also contributes HTML development and illustrations on an hourly basis. Except for DiBiase, none of the faculty members had prior experience with computer-mediated teaching. The current three part-time and two full-time faculty members are barely sufficient to deliver the four-course program. As enrollments grow, we plan to employ one part-time instructor and one full-time assistant to maintain and deliver each course. Recruiting additional faculty members to teach existing courses and to develop new ones is one of the most challenging problems facing the GIS Program.

\section{Support}

The World Campus is seen as a cost center within the University. It is responsible for all costs related to course development, delivery, and support. The World Campus works with the sponsoring academic unit to develop a budget to support faculty and other costs within the academic unit, as well as World Campus costs for program development, student support, marketing, and technology infrastructure. The budget and scope of work for each program represents a consensus between the academic unit and the World Campus. 
The financial support model also includes a revenue-sharing plan under which the academic unit receives, initially, $50 \%$ of all net income. Once initial program development costs are recovered, this increases to $80 \%$. The purpose of this model is to provide academic units with a new source of income to incentivize their participation and support.

The World Campus uses a program team approach to instructional development. This team includes a senior faculty coordinator who serves as the primary liaison with the academic unit and with other participating faculty. Other members of the team include a World Campus program manager who is administratively responsible for the program; a program-marketing manager who is responsible for promotion and marketing; a representative of Distance Education Student Services; and an instructional designer. A single instructional designer works with all faculty in the program to facilitate consistency and synergy among courses. The instructional designer and faculty may also call on a World Campus resource team of programmers, graphic artists, editors, technical typists, and other media and technology specialists.

While the long-range plan for the World Campus assumes that most faculty who teach World Campus courses will do so as part of their normal teaching load, salary supplements and support for technical assistance were provided to entice faculty into developing and teaching these courses. The costs associated with operating the Certificate Program in TM included partial salaries for five faculty plus full salary for one instructor, along with funds to support one half-time wage-payroll graphic designer. For the Certificate Program in GIS, these costs included three partial and two full faculty salaries, as well as purchases of computing equipment, peripherals, and software. Faculty participation in professional conferences, marketing trips to professional association meetings, and other relevant activities are also covered.

Recently the World Campus created FADEV 101, a six-week, on-line course for faculty designed to help them better understand ALN teaching before they get involved in a program. This course helps faculty understand the nature of ALN and the personal and professional commitment that is needed to be successful. The World Campus is also taking several steps to encourage faculty to work together to shape the future of ALN at Penn State. The World Campus director of academic programs convenes general World Campus faculty meetings three times per year and meets regularly with key Faculty Senate and Graduate Council committees.

The World Campus also provides a broad range of on-line support for students, including on-line registration and technical support. World Campus Student Services staff is responsible for responding to technical and administrative problems and coordinating logistics for materials delivery, submission and return of assignments, and proctoring of examinations. This level of noninstructional support is critical to the overall success of the program.

\section{Enrollments}

The World Campus was launched in January 1998 with a pilot semester that included initial courses in four certificate programs. During the first full academic year, the World Campus offered 33 individual courses in eight certificate programs. Almost 900 people were admitted to these programs by the end of the fiscal year. The World Campus goal is to offer as many as 30 degree and certificate programs, comprising 300 courses and generating 10,000 course enrollments per year by 2003. The TM Certificate Program has had 214 course enrollments since its startup in January 1998. Since the GIS Program began in January 1999 there have been 188 enrollments.

\section{E. Learners}

The World Campus is directed primarily to students for whom a traditional campus experience is either inconvenient or geographically impossible. Students come from all corners of the United States and from other countries as close as Canada and as distant as China and Malaysia. In the case of TM, one course was also offered to residential students at Ohio State University through the CIC Common Market of Courses, an experimental program among Big Ten institutions to share the use of technology-based courses across institutions.

Learners in the TM program differ substantially from on-campus learners. Their ages range from late teens to early 50 s. While nearly all are fully employed on golf courses or in some other facet of the turfgrass industry, some are 
students at other institutions or on temporary leave from full-time study. Their goals range from acquisition of college degrees and/or professional certification to simply becoming more knowledgeable in turfgrass science and technology. While some are proficient in the use of computers, others are new to computer technology and find computer-based learning very challenging at first. This is most evident in the introductory course (TURF 235). Surprisingly, if given the opportunity, the more proficient ones are eager to teach those encountering problems. By encouraging students to work together in teams at the very beginning of the course, the demands on the instructor's time for dealing with computer problems have been dramatically reduced. It is also important to establish standards of participation and performance in the first week or two to ensure that students complete their assignments and interact in a timely and satisfactory fashion.

Students enrolled in the GIS Program range in age from mid-20s to mid-50s. Most have full-time jobs that already involve use of geographic information technologies, but lack formal education in the field. Some seek to start new careers. Students log into the course in the early mornings before work, evenings after work, or weekends. Some are permitted to study during work hours. Many students enter the program with considerable skepticism about the amount of attention and the quality of the instruction they will receive. We have found that the instructor of the introductory course needs to work hard to assure students that they are not learning in isolation and that the instructor will be responsive and accommodating to individual circumstances. Also, it seems clear that students who believe they are pioneers in an innovative enterprise are more likely to forgive the inevitable technical obstacles that arise in on-line learning.

\section{METHOD}

\section{A. Technology and Infrastructure}

World Campus courses use a variety of technologies to present information, give students access to learning resources, facilitate interaction, and provide administrative support. The emphasis is on creating a highly interactive learning community that uses resources to inquire about issues, solve problems, and work on collaborative projects. Currently, WebCT and First Class are the two primary software platforms for World Campus courses. While most upper-division courses and all graduate courses are cohort-based, some lower-division courses use a rolling enrollment approach, giving students the maximum flexibility while ensuring their access to a community of interest.

Students gain access to the World Campus through the Internet. They must have an Internet service provider and an appropriate browser (typically Netscape Navigator or Internet Explorer). All courses are located on a secure Penn State server. Upon admission into a program, students receive a Penn State access account that gives them access to Penn State's on-line library services and other resources. Upon registration in a course, they also receive a course password that allows them to enter the learning environment.

All of the turfgrass courses are Web-based and the course delivery platform is WebCT. Students are asked to secure computers with specified minimum technical requirements. The courseware includes lessons (containing graphicintensive instructional modules patterned after classroom lectures, and formative quizzes) for acquiring recall and concept knowledge, and exercises (practicums, laboratory exercises, and decision cases) for developing problemsolving and critical-thinking skills. To date, streaming video and other multimedia enhancements have been avoided because of bandwidth limitations and concerns. All courseware is maintained on a series of servers based in the institution's Center for Academic Computing.

The content of the GIS Certificate Program courses includes lessons, quizzes and exams, activities, bulletin boards, and E-mail communications. Lessons are analogous to lectures, but consist of text and graphics rather than "talking heads." No streaming video or audio presentations are employed. Students access lessons via a secure course WebCT site on the World Wide Web. Typically, students compile and print the lessons, then read the printed copy. The lessons include many links to Web sites published by organizations that produce and use geographic data. Students return to the WebCT site to follow the links. Lessons in the first course of the four-course sequence include 
frequent, ungraded, multiple-choice-format practice quizzes. The lessons conclude with quizzes that are automatically graded. The first course concludes with a final exam in the same format.

As students progress through the four courses, the proportion of course content devoted to lessons and quizzes decreases and the emphasis on student activities increases. Activities are tutorial assignments that culminate in deliverables which students are required to submit to the instructor as E-mail attachments or as HTML pages published in a course gallery. For instance, students in the second course are required to use an authentic GIS software package to digitize features shown on a scanned map and then submit the file to the instructor as proof of their ability to perform the task. By arrangement with a leading GIS software vendor, students are able to purchase authentic GIS software at nominal cost from the University's bookstore. In addition, the program ships data needed to complete assigned activities to students on CD-ROM.

The quality of communications among students and between students and instructors is a crucial factor in students' perceptions about the quality of an ALN experience. In both TM and GIS Certificate Programs, communications take place in either a bulletin board space of the WebCT site — which supports threaded discussions — or via E-mail. Chat is used sparingly or not at all because it requires students to meet at the same time. Threaded discussions, by contrast, are very fruitful. Often hundreds of messages are exchanged among students over a 10- to 12-week course. Instructors can foster a sense of community by encouraging students to check the threaded discussion list daily and to contribute to discussions regularly.

\section{B. Content Delivery}

In the introductory turfgrass (TURF 235) course, students access designated lessons and complete the associated quizzes by the due dates published in the course calendar. The results of the quizzes are automatically recorded in the student database, thus indicating completion of the lesson and the level of recall and comprehension of the material. Summative exams include two-hour exams (50 points each) and a final (100 points) taken under the supervision of a local proctor. Answers to assigned questions in the five practicums are posted to the bulletin board for review and critiquing by students in five-member groups. After revision, the instructor critiques the answers. Students receive up to 10 points for the initial answer, up to 10 points for participating in the critiques, and up to 20 points for their final answer, for a total of 40 points for each of the five practicums. Since the exercises draw upon the material covered in the lessons and involve frequent interaction among students and between the students and the instructor, they have become the centerpieces of each course. In the capstone course (TURF 436), after completing an orientation case, students select three decision cases from the 11 currently available (and develop their own topic case) and post the reports and attachments to the bulletin board. Following completion of each case, the instructor assigns several questions based on each student's case reports. The answers are handled in much the same way as the practicums in TURF 235: students receive points for their initial answers, participation in the critiques of their groupmates' answers, and their final answers. The other courses employ elements from both the introductory and capstone courses.

In the GIS Certificate Program, quizzes and activities involve deliverables that must be submitted by specified dates. We are convinced that weekly deadlines are necessary; several students have remarked that they relied upon deadlines to justify attention to the course when many other responsibilities were competing for their attention. From an instructor's standpoint, the rhythm of the courses is distinctly different from resident instruction. Faculty members who are used to confining their attention to students to teaching days find it challenging to adjust to the necessity of daily interactions with off-campus students. And there is no question that daily interactions are required. Portable computers equipped with modem ports and Ethernet cards should be standard equipment for ALN instructors. At the outset of the GIS Program, when development of declarative knowledge is emphasized, faculty members rely primarily on automated multiple-choice quizzes and exams to assess student performance. As the program progresses through the second, third, and fourth courses, however, emphasis shifts from declarative to procedural knowledge, which we evaluate by personally inspecting individual student project deliverablesincluding reports and digital files produced with GIS software. Just as with traditional resident instruction, one of the greatest creative challenges confronting ALN teachers is to identify authentic deliverables that reveal a lot about 
students but are easy to evaluate. We have found that it is worthwhile to teach students how to produce HTML pages and publish reports on the Web in a course gallery. Public exhibitions motivate students to do more careful work and enable them to inspect and learn from, each other's projects.

\section{Organization and Evolution}

The World Campus is organized within the Department of Distance Education at Penn State. Distance Education is administered by Outreach and Cooperative Extension, which includes centralized market research, client development, and marketing communications functions that support the World Campus. Support for the course development function and the technology infrastructure represents a partnership between the World Campus and the University-wide Center for Academic Computing.

Like other World Campus courses, the responsibility for TM and GIS resides in the home academic units, which are responsible for faculty assignment, curriculum, and overall academic approval and quality. While the responsibility for the content of each course resides with the instructor, the instructor shares the responsibility for course development with the instructional designer responsible for developing standardized presentation formats for the various components of the courses and for integrating materials within the WebCT delivery platform. Others, including computer-graphics personnel, work in support or advisory roles. With respect to the set of courses comprising each program, the faculty coordinator provides leadership in structuring the curriculum in consultation with department administrators, faculty, and the instructional designer.

The introductory course in the TM Certificate Program (TURF 235) has been taught five times, while TURF 334 and 436 have been taught three and two times, respectively. The structure of TURF 235 and 334 have remained the same since the courses were introduced; however, systems were put in place to enhance their efficiency and effectiveness. For example, weekly messages, critiques, timely tips, and other messages are stored in electronic desktop files for easy retrieval and use. A tracking system has been developed using a spreadsheet, also accessible on the computer desktop, for recording students' activities on exercises. TURF 436 was restructured to eliminate the preparation of group reports due to problems encountered during its first offering. The lesson learned was that the success of group activities should not be entirely dependent on any one student. For example, if a particular student fails to prepare his portion of a report, the entire group suffers; however, if that student fails to participate in the critique of another student's answer to an assigned question, the exercise can still succeed as long as most of the other students participate.

The GIS Certificate Program has recently begun its third quarter of operation. By January 2000, all four courses will be offered quarterly. Our growth strategy involves adding support for a second GIS software program and developing additional courses at the advanced level. As discussed earlier, specialized GIS software is a fundamental component of a geographic information system. No one vendor serves more than about one-third of the GIS software market at present; future trends are uncertain. Starting in January 2000, we will begin to develop a second, parallel track through the Certificate Program that is based on a second GIS software package. By July 2000, we will provide education based on two products produced by vendors that together account for approximately $60 \%$ of the GIS software market. Students will be asked to choose one product or another at the beginning of the program. We expect that the GIS faculty will need to be increased to one part-time instructor and one full-time GIS specialist to develop and maintain the dual tutorials associated with each course. We also plan to develop additional advanced courses, such as GIS Programming, Business Applications, Transportation Applications and others, depending on the availability of new, qualified faculty members. By January 2002, we hope to begin offering advanced courses to qualified students without prerequisites. Our goal is to attract 1000 enrollments per year by 2002 (400 annually in the first course, 280 in the second, 200 in the third, and 140 in the fourth). 


\section{RESULTS}

\section{A. Student Response}

Both telephone and E-mail surveys were used to collect data from students who had successfully completed TURF 235. The most important factor influencing students to enroll in the course was convenience. Also important were accessibility and the reputation of the institution and the instructor. They also cited the importance of interaction among students and between the students and the instructor.

Students in the spring 1999 offering of the introductory GIS course were surveyed to find out how much effort the course required, how students felt about the required effort, and what they liked most and least about the experience. Twenty-nine students responded to the survey. Forty-one percent stated that they worked from four to eight hours per week; $38 \%$ stated nine to twelve hours. The actual effort required was close to the intended workload, and $79 \%$ of respondents felt that the level of effort was "just about right." Comments on what students like most and least were uniformly constructive and encouraging. Students enjoyed most aspects of the networked medium; one student who especially appreciated the lesson links to external Web sites remarked, "I had no idea there was that much information available" on the Web. Others liked the instantaneous feedback provided by automated quizzes, although one complained "there are better explanations if you get the question wrong than if you get it right." One student confessed to being pleasantly surprised by the quality of communications, stating, "I felt like I was a participant in the class more than any [face to face] class I've taken lately." Complaints focused on the instructor's occasional tardiness in delivering promised materials and on the slow performance and seemingly frequent downtime of servers.

\section{B. Faculty Response}

With respect to faculty satisfaction with the TM program, all who have participated to date are enthusiastic about distance education generally and Web-based instruction specifically. Despite the fact that you cannot see or hear your students, you do get to know them quite well through their words and their activities. As you monitor the interaction among students, you see examples of professional as well as unprofessional behavior. Through your interaction with students, you can demonstrate professional behavior and, thus, teach by example. When students attempt to put what they know into words, they reveal their command of facts, their understanding of concepts, and their ability to apply what they have learned to analyze a problem and develop an appropriate solution. Each demonstration of knowledge provides the opportunity to assist students in their professional development. Most of us have been surprised at how effective Web-based instruction can be. Unlike classroom instruction, students cannot hide in the back of the class. Everything they do is visible and, thus, subject to some response by the instructor, should he or she take advantage of the many opportunities to help students to learn.

Faculty satisfaction is uneven in the GIS Program. The faculty coordinator-who designed the program and who has the most at stake in its outcome - is most gratified by its early success. Other faculty members are less enthusiastic. They worry that the heavy workloads involved in launching the program may not ease after the initial courses are complete. They wonder how long it will be before the novelty of communicating with students by E-mail every day wears off. The original World Campus plan called for the use of teaching associates to support growth of enrollments in individual courses; the GIS Program is likely to be one of the first programs where this need is addressed.

In addition, all GIS faculty are offended by the University's expectation that faculty authors will sign away intellectual property rights through the University's standard "work for hire" copyright agreements. A Universitywide Intellectual Property Task Force is addressing this concern through review of current copyright policy. And because the GIS Certificate Program remains peripheral to the operations of the Department, faculty members have received little recognition for their accomplishments so far. Faculty satisfaction is a crucial concern, since, in light of the perceived lack of incentives, it will be difficult to replace faculty members who may choose to leave the program for other opportunities. On the other hand, if the program is able to build upon its early successes and earn not only revenues, but also recognition for educational excellence, faculty rewards and satisfaction are apt to increase. 
The World Campus has now completed its first full year of operation as Penn State's 25th campus. Fourteen programs are now either being offered or scheduled for launch in the coming year, including the first World Campus master's Degree (in Adult Education). Development will begin on five additional programs in the new academic year. As the World Campus expands, the experiences of faculty in TM, GIS, and other early programs are helping to shape both process and policy.

\section{ISSUES}

\section{A. Teaching Effectiveness}

Faculty members with no experience in Web-based distance education are likely to ask, "Can you really teach students whom you can neither see nor hear?" Those of us who have been teaching for many years may remember when we first started - eyeball-to-eyeball contact was emphasized, as was the importance of using your students' facial expressions as a measure of how well you were doing. This and other forms of body language or nonverbal communication provided feedback by which to guide the direction and flow of a presentation. But in Web-based, distance education, communication is asynchronous and, thus, other tools must be employed. For example, lecture material may be covered through student-centered learning resources called instructional modules. These modules may, in turn, be incorporated into lessons that provide an introduction to the material, including a series of questions that establish learning objectives. The lessons may conclude with formative quizzes, which assess student recall and concept knowledge and, thus, are themselves valuable learning resources. And the lessons may be complemented by practicums comprised of questions to which students respond by applying what they have learned from the lessons to solve puzzles or problems. Students in small teams can work practicums collaboratively, so that each student functions as both learner and instructor with respect to his or her teammates.

The difference between conventional classroom instruction and Web-based distance education is as great as the difference between driving a car and flying a helicopter. While some of the skills one acquires from driving may be applicable to flying, they are not by themselves adequate; thus, transitioning from one to the other requires the acquisition of additional skills. Similarly, transitioning from conventional classroom instruction to Web-based, distance education requires the acquisition of skills specific to this new teaching mode. It is important to emphasize, however, that the destinations, pedagogically speaking, are the same; we are simply employing different vehicles and routes by which to get there. An additional bonus from learning new teaching skills through involvement in Web-based distance education is that some of these skills can enrich conventional classroom instruction. For example, in discussion classes in which questions are employed to systematically lead students through an analytical process, critical points are usually listed on a blackboard. Since the asynchronous environment of the Web is not well suited to an intense discussion class, concept mapping, learned through a tutorial on the Web, has been successfully employed to teach these same skills. And successful use of concept mapping on the Web can lead to its use in the classroom in place of the conventional blackboard lists. As a consequence, both teaching modes have benefited from and been transformed by attempts to develop effective Web-based instructional methodologies.

\section{B. Relationship with Students}

In Web-based distance education, despite the fact that you can neither see nor hear your students, you can get to know them quite well through their words. The way they express themselves and the ways in which their words are organized to form sentences provide insight into how they think. A student's ability to draw logical conclusions from an analysis of a problem or problematic situation or present defensible arguments in support of a particular course of action is largely revealed through his or her words. And by reacting appropriately to their words, we can shape the mental processes that give rise to those words.

\section{Satisfaction with Product}

One systematic approach to assessing faculty satisfaction is to consider how distance teaching affects the quality of the relationships that give meaning and purpose to our lives. For example, a teacher might consider the extent to which distance teaching improves, detracts from, or has no effect on relationships with students, collaborators, 
departmental and disciplinary colleagues, institution, family, community, and the products of his or her work. A satisfactory relationship with the products of one's work follows when instructors have access to the resources they need to produce and maintain quality instructional products. It is unrealistic to expect that ALN materials are ever "finished." The experience of faculty members involved in these programs indicates that revision of on-line materials is necessarily a continuous process. Faculty members' satisfaction with the products of their work also depends on the extent to which they retain authority over the work after it has been delivered to students. This concern raises the issue of intellectual property policy, which we consider below.

\section{Compatibility with Other Responsibilities}

Relationships with family, friends, and community are likely to suffer if a teacher spends too much time at work, and teachers are likely to be dissatisfied with distance teaching if they perceive it to require an inordinate amount of effort. Several studies presented at the Sloan ALN Summer Workshop consistently reported that faculty members perceive distance teaching to be more work than face-to-face delivery. However, despite anecdotal evidence and tabulations of perceived effort, no one really knows yet whether distance teaching is more work or less. Studies of this sort should be high priorities in the ALN research agenda as current on-line courses mature.

\section{E. Ethical Concerns}

Faculty members tend to be thoughtful and conscientious people. They are not likely to be satisfied with distance teaching if they feel it is a morally suspect enterprise, as some suggest [2]. Rather than dismissing such claims, it is important that leaders be able to articulate compellingly how ALN addresses legitimate social needs. Many of these needs have been articulated in the Kellogg Commission's report "The Engaged University."

In an information society, continuing education has become both an individual and a social imperative. ALN allows institutions to extend their educational resources to working adult students in response to this need. In addition, institutions are recognizing that effective participation in an information society demands citizens who can find, evaluate, and use information to create the new knowledge needed to solve new programs. ALNs support an active, collaborative learning environment that builds these skills in students, on campus and off. It is important that ALN be seen as a response to these needs and not just as a new way to generate income.

\section{F. Incentives and Rewards}

Financial and other incentives do exist and play a role in encouraging faculty members to respond positively to opportunities in Web-based, distance education. The principal reward that makes distance education so satisfying, however, is the opportunity to extend the reach of your teaching to students who otherwise would not be able to learn from you. As these students may be from anywhere in the world, incorporating them into your classes can result in a geographical and cultural blend from which each participant, including the instructor, can learn.

\section{G. Working in a Team Effort}

Independence of thought and action is a basic tenet of academic freedom. While most faculty understand and appreciate the principle of shared authority that underpins the life of an academic community, they also value their independence in the classroom. The technical complexity of ALNs, however, requires that faculty work in a team environment. An on-line course represents the collaborative work of faculty and nonteaching professionals. This has both philosophical and operational implications. Philosophically, the team environment requires that members understand each other's roles, responsibilities, and authority. The faculty member's authority over the content and objectives of the course is absolute, but in this environment, it is also informed by the expertise of instructional designers, programmers, graphic artists, editors, and others who contribute to the final work. At the operational level, faculty must accommodate the needs and time constraints of other team members.

\section{H. Required Support Services}

The ALN environment places new demands on faculty for instructional development and delivery. In order to ensure success, institutions have the obligation to provide faculty with basic support services. Faculty should be provided with release time or extra compensation to accommodate the workload associated with course development. Beyond 
that, faculty should have ready access to equipment, software, and human resources to help create ALN-based courses. Among essential human resources are instructional designers, software application specialists, graphic artists, text editors, and other technical specialists. These should be provided as part of the institution's ALN infrastructure. In addition, institutions should provide professional development opportunities to help faculty members build their course construction and teaching skills. The need for support continues into the course delivery process.

Faculty members should have access to the technical support they need to respond to problems that may arise. If the ALN program is directed to off-campus students, the institution must also arrange for a variety of additional support services, from registration, records and materials distribution to support for lesson transmission, testing at a distance, etc. Penn State employs more than 100 professionals who devote a significant portion of their workload to support World Campus students and instructors. This human infrastructure includes specialists in marketing, marketing research, marketing communications, client development, student services, technical support, and instructional design. Faculty members who understand that their efforts are supported by a quality professional staff are more likely to be satisfied than faculty members who feel that they are going it alone.

Faculty members active in their professions travel often. Portable computers should be standard equipment for ALN faculty, so that they can stay in touch with students while on the road.

\section{Perception by Colleagues}

An important concern expressed by many faculty members is embodied in the question: "Will faculty become roadkill on the information superhighway?" This assumes that computers can actually replace teachers. It fails to recognize that the role of a teacher in the educational process is not to simply show and narrate slides (something that a computer can do), but to effect learning through interaction with students. In Web-based, distance education, this interaction typically begins with monitoring student activity, as well as student performance on quizzes and problem-solving exercises. The instructor can then respond by motivating (encouraging them to keep up with their assignments), intervening (getting them back on track when it becomes obvious that they have gotten off course), critiquing (providing feedback on the quality of their work), and responding (answering their questions, perhaps by pointing them in the right direction).

Within individual academic units, ALN teaching should not be perceived as a peripheral activity. Instead, it should be viewed as part of the unit's normal, ongoing teaching function. Penn State's World Campus is directed primarily at off-campus students. Penn State has structured the World Campus so that successful ALN programs will become a new income source for the academic unit, with the goal that this will increase the perceived value of this kind of teaching by faculty peers. Penn State is also creating policies that facilitate the use of World Campus courses by oncampus students, adding value to the more traditional teaching roles.

\section{J. Is This Scholarly Work?}

Preparing Web-based courseware is analogous to writing a book. Learning and/or developing new teaching techniques is analogous to learning and/or developing new experimental techniques. In Scholarship Reconsidered: Priorities for the Professorate, Ernest L. Boyer distinguished among different types of scholarship - discovery, application, integration, and teaching [1]. Web-based instruction involves all four.

In 1995, the National Research Council (NRC) ranked Penn State's Department of Geography as the number one graduate program in the United States. The ranking was based on two criteria - perceived quantity and quality of research publications and quantity and quality of Ph.D.s produced. The Department's current strategic plan consists of a single goal - to retain the Department's ranking through the next round of NRC rankings in 2005. Few, if any, faculty members perceive participation in distance education programs as a way to achieve this goal. However, if the Certificate Program in GIS achieves its goals, it will generate a revenue flow so substantial that all faculty members will be compelled to take notice. Instead of waiting for the academic culture to change so that teaching is valued on 
a par with research, a more fruitful strategy for ALN advocates may be to create sound business plans. Economic benefit, along with demonstrable excellence, is the key to fostering faculty acceptance of ALN.

\section{K. Opportunity Cost for Faculty}

The World Campus focuses on programs for which the University has an established reputation for excellence. Most often, they are also programs in which the faculty have strong research programs and are in high demand. Opportunity cost is, as a result, a significant issue, since World Campus programs involve multiple faculty in a longterm commitment to delivering certificate and degree programs. For this reason, the World Campus works at all levels within an academic unit to ensure that a program fits within the strategic goals of the unit. The program must be accepted as an ongoing function of the academic unit.

\section{Reward from Institution}

The first and most important reward from the institution is the recognition that teaching in the World Campus is recognized as part of the faculty member's teaching role in the promotion and tenure process. The Penn State Faculty Senate has included this in its new promotion and tenure policies. The next step will be to equate the development of ALN course materials with publishing a textbook. Access to new professional development opportunities and support services associated with expanding teaching roles provide an additional, overt, and immediate institutional reward.

\section{Intellectual Property}

Intellectual property is a serious issue for many institutions that participate in ALN. Course development is a team effort that involves significant use of University resources to support the work of the faculty member. Penn State currently has a University-wide Intellectual Property Task Force that is reviewing all intellectual property issues, including development of on-line courses. The overriding issue is how best to protect the interests of the faculty, the University, and the students.

Among the main issues that concern both administration and faculty are the need for better definition of what is covered by a copyright and what remains the property of the individual faculty member, the ability of faculty to use copyrighted material in other University-related work and in individual scholarly work, protection of third-party copyrighted materials incorporated into ALN courses, and protection of student rights when they contribute to a work. The intellectual property issue is made more complex by the entry of private companies into the on-line education and training arena. Increasingly, faculty members are torn between their commitments to the University and opportunities to work with commercial firms.

\section{N. On-Load versus Extra Compensation}

Penn State's World Campus is conceived as a fully integrated element of Penn State's academic community-the 25th campus of the University. As a result, the goal for World Campus programs is that it be integrated into the core academic units of the University and that faculty members participate in the World Campus as part of their normal teaching workload.

\section{REFERENCES}

1. Boyer, E. L. Scholarship Reconsidered: Priorities for the Professorate. San Francisco: Jossey-Bass, Inc., 1997.

2. Noble, David F. Digital diploma mills: The automation of higher education. First Monday, Accessed January 21, 1998, http://www.firstmonday.dk/issues/issue3_1/noble/index.html\#d3.

\section{ABOUT THE AUTHORS}

Alfred Turgeon grew up on a golf course and worked at Metropolis Country Club in White Plains, NY, through his high school and college years. He majored in Turfgrass Management at Rutgers University where he earned his 
B.S. degree in 1965. Graduating with an R.O.T.C commission, he then served a three-year tour in the U.S. Army (including one year in Vietnam) as an infantry officer, helicopter pilot, and meteorology instructor. He resumed his graduate study at Michigan State University where he earned his Ph.D. in 1971. His first professional position was at the University of Illinois as Assistant, then Associate, Professor of Turfgrass Management. He then moved to Texas where he was Professor and Resident Director of Research at the Texas A\&M Research and Extension Center at Dallas from 1980 to 1983. He then joined the Tru Green Corporation as Vice President for Research and Technical Services from 1983 to 1986. His next move was to The Pennsylvania State University where he served at Professor and Head of the Department of Agronomy. In 1994, he resigned from his administrative position to devote himself full time to turfgrass education and associated pedagogical research and development, with emphasis on innovative computer-based and inquiry-based learning resources and techniques. Dr. Turgeon has over 250 publications, including a popular textbook entitled: Turfgrass Management, now in its fifth edition. He currently serves as Senior Faculty Coordinator of the Penn State World Campus's Turfgrass Certificate Program, a web-based series of undergraduate courses with students enrolled from all over the world.

Contact: Department of Agronomy, The Pennsylvania State University, 116 ASI Building, University Park, Pennsylvania 16802; Telephone: 814-863-7626; Fax: 814-863-7043; E-mail: aturgeon@psu.edu; URL: www.cas.psu.edu.

David Di Biase is Senior Lecturer, Geography at The Pennsylvania State University. He was trained as a cartographer at the University of Wisconsin-Madison in the 1980s. He has since realized that maps are a special case of distance education. At Penn State, he teaches both resident and distance versions of a general introduction to geographic information science. He also directs the George F. Deasy GeoGraphics Laboratory, an information design studio whose professional and student employees create educational software, World Wide Web sites, and print cartography for clients on campus and off. In 1999 he was honored with the Media Achievement Award of the Association of American Geographers.

Contact: Department of Geography, The Pennsylvania State University, 302 Walker Building, University Park, Pennsylvania 16802; Telephone: 814-863-1790; Fax: 814-863-7943; E-mail: dibiase@psu.edu.

Gary Miller is Associate Vice President for Distance Education and Executive Director of the World Campus at The Pennsylvania State University. He also serves as Affiliate Associate Professor of Adult Education. Dr. Miller holds a Doctor of Education degree in Higher Education from Penn State. He is the author of The Meaning of General Education: The Emergence of a Curriculum Paradigm (Teachers College Press, 1988) and has contributed chapters on continuing and distance education for five books published in the U.S. and the United Kingdom. He has presented numerous papers on undergraduate curriculum, continuing education, and distance education at national and international conferences. Dr. Miller currently serves on the Executive Committee of the International Council for Distance Education and the Board of Directors of the Midwest Universities Consortium for International Activities, Inc. Over the past few years, he has chaired the Commission on Principles of Good Practice in Continuing Education for the National University Continuing Education Association and has served on the Taskforce on Quality Principles in Distance Education for the American Council on Education and on the Taskforce on Distance Learning for the Middlestates Commission on Higher Education. Prior to assuming his current responsibilities, Dr. Miller served as Executive Director of the International University Consortium and Associate Vice President for Program Development at the University of Maryland University College.

Contact: Outreach and Cooperative Extension, 211 Mitchell Building, The Pennsylvania State University, University Park, Pennsylvania 16802; Telephone: 814-863-3248; Fax: 814-865-3290; E-mail: gem7@outreach.psu.edu. 


\title{
Introducing the Penn State World Campus through Certificate Programs in Turfgrass Management and Geographic Information Systems
}

\author{
Alfred Turgeon, David Di Biase, Gary Miller
}

\section{Discussant: Richard Lytle, Oregon University System}

It may be useful to consider "Faculty Satisfaction" from two perspectives. The first perspective is student learning/student satisfaction. Indeed, student learning should be the driver not only for ALN teaching, but for all teaching. An earlier speaker said something to the effect that faculty satisfaction and student satisfaction are functions of each other. So, we assert that the major driver of faculty satisfaction should be student satisfaction—or student learning. For example, even a higher level of effort for ALN may be expected to increase faculty satisfaction, so long as the level of effort required is reasonable and that the effort itself is an exciting teaching and learning experience.

The second perspective on faculty satisfaction encompasses issues that are not directly tied to student learning, but can be seen as contributing to both student and faculty satisfaction. For example, automatic grading in large classes may give the faculty member more time for interaction with students, and judicious use of simulations may be a cost-effective initial learning exercise upon which the faculty member builds a very rich learning and collaborative experience. More prosaic examples are policies and procedures that avoid avalanches of E-mail on the faculty, and industrial-strength technology that promotes uninterrupted learning on the network.

The second perspective or category of faculty satisfaction can degenerate. Sometimes it appears that release time, pay and other incentives for participating in ALNs are offered to buy non-participating faculty. Extra pay seems questionable in the absence of evidence that ALN teaching requires more time - and in the absence of evidence that most faculty are suffering from overwork in their regular teaching responsibilities. A better strategy would be to find dedicated teachers who want to participate, accepting lower growth rates for ALNs if necessary.

Most of the educational institutions participating in the workshop fell into one of two categories: universities that value research, publication and production of doctoral students more than teaching and universities that regard themselves as primarily teaching institutions. The Penn State paper describes this situation (on the research side) with much more candor than most. In these universities, ALNs are mostly progressing slowly in the key disciplinary areas and occasional faculty revolts are covered by the media. Other papers from teaching universities report rapid growth of ALNs and widespread acceptance by faculty and students. It is difficult to avoid the conclusion that many of those whose institutions place high value on teaching find ALNs very attractive while many of those whose institutions place lower priority on teaching prefer traditional approaches. The struggle is more about the value of teaching than it is about ALNs.

For ALN advocates, the bigger picture described above does not really alter tactics. We must look for major ALN advances in universities that value teaching very highly and develop the best possible programs in those universities. We must also look for faculty who value teaching in research universities and coach them into use of ALNs.

Richard (Dick) Lytle is Director of the Oregon Master of Software Engineering Program. Previously at Drexel University in Philadelphia, Dick was Dean of the College of Information Science and Technology and most recently was Director of Information and Software Systems Programs in the College. Before coming to Drexel, Dick was Director of Information Resource Management at the Smithsonian Institution, where he was responsible for IT planning, central computing and telecommunications. Dick also developed and directed information management programs at Washington University, Rice University and the State of Illinois. 
Contact: Oregon College of Engineering \& Computer Science, Oregon University System, CAPITAL Center, Room 1313, 18640 Northwest Walker Road, Beaverton, Oregon 97006-1975; Telephone: 503-725-2901; Fax: 503-7252910; E-mail: lytler@capital.ous.edu. 